\title{
Estimated Financial Impact of Trypanosoma vivax on the Brazilian Pantanal and Bolivian Lowlands
}

\author{
Andrew Seidl $/{ }^{+}$, Alberto MR Dávila* ${ }^{++}$, Roberto AMS Silva ${ }^{* *}$
}

\author{
Department of Agricultural \& Resource Economics, Colorado State University, Ft Collins, CO, 80523-1172, \\ USA *Embrapa/Centro de Pesquisa Agropecuária do Pantanal, Corumba, MS, Brasil **Embrapa/Centro \\ Nacional de Pesquisa de Suínos e Aves, Br 153, km 110, 89700-000 Concórdia, SC, Brasil
}

The financial impact of the first outbreak of Trypanosoma vivax in the Brazilian Pantanal wetland is estimated. Results are extended to include outbreaks in the Bolivian lowlands providing a notion of the potential influence of the disease and an analytical basis. More than 11 million head of cattle, valued at more than US\$3 billion are found in the Brazilian Pantanal and Bolivian lowlands. The total estimated cost of the 1995 outbreak of T. vivax is the sum of the present values of mortality, abortion, and productivity losses and treatment costs, or about $4 \%$ of total brood cow value on affected ranches. Had the outbreak gone untreated, the estimated losses would have exceeded 17\% of total brood cow value.

Key words: Trypanosoma vivax - economic losses - Brazil - Bolivia - financial impact

The Brazilian Pantanal and Bolivian Lowlands are located in the center of South America. Covering more than $250,000 \mathrm{~km}^{2}$, the region is dominated by extensively managed cattle ranches and approximately 11 million head of cattle. In addition to common management practices, topography and weather patterns, the ranches in the Brazilian Pantanal and Bolivian lowlands trade with one another, share markets and transportation routes, and disease management strategies. Outbreaks of disease in the Pantanal are likely to spread to the Bolivian lowlands and the converse. The risk profile and effect of disease outbreaks are likely to be similar across the two regions.

Typanosoma vivax was identified in the Brazilian Pantanal for the first time in 1995, in an outbreak on seven ranches in the northern subregion of Poconé, State of Mato Grosso (Silva et al. 1995, 1996). Subsequent outbreaks were reported in the Bolivian lowlands and the southern Pantanal (Silva et al. 1998a, b). In order to provide a notion of the potential influence of the disease and an analytical basis for future work, the financial impact of this outbreak is estimated and, then, results are extrapolated to the broader region.

\footnotetext{
${ }^{+}$Corresponding author. Fax: +970-491.2067. E-mail: aseidl@ceres.agsci.colostate.edu.

${ }^{++}$Present address: Departamento de Bioquímica e Biologia Molecular, Instituto Oswaldo Cruz, Av. Brasil 4365, 21045-900 Rio de Janeiro, RJ, Brasil.

Received 12 November 1998

Accepted 19 January 1999
}

\section{MATERIALS AND METHODS}

Study site - In June 1995, ranchers reported symptoms typical of the disease including: progressive emaciation, anaemia, fever, lethargy, and loss of appetite and dysentery (Figure). The ranches were small by local standards, maintaining an average herd of 343 head per ranch. All ranches were located along the principal transportation route to Bolivia and regional markets. Samples were collected from each ranch and examined by microhematocrit test. All ranches and $34.5 \%$ of the animals sampled (10/29) tested positively for $T$. vivax. Ranchers reported nine brood cow deaths and 19 calf abortions prior to diagnosis and treatment. All remaining cattle were treated with diminazine and survived (Silva et al. 1996).

Productivity effects of T. vivax - T. vivax results in financial losses to the rancher in terms of lost productivity including abortion, infertility, and death of cows and calves (Ogwu et al. 1984, 1986, Ogwu \& Njoku 1987). Perhaps due to the timing of the high vector season and the principal breeding period, Pantanal brood cows have been observed to lose one year of productivity due to $T$. vivax infection; we assume this outbreak renders an estimated $34.5 \%$ of all cattle on the seven ranches infertile for one year. Financially, the effect is the same as predicting an abortion for all infected cattle for the year following an outbreak. However, not all of the cattle infected this year would have calved successfully next year. The estimated annual calving rate in the Pantanal is $37.3 \%$ and $26.7 \%$ of these calves can be expected to die on average (Almeida et al. 1996). As a result, an estimated $9.6 \%$ (27.3\% of $34.5 \%)$ of all brood cattle 


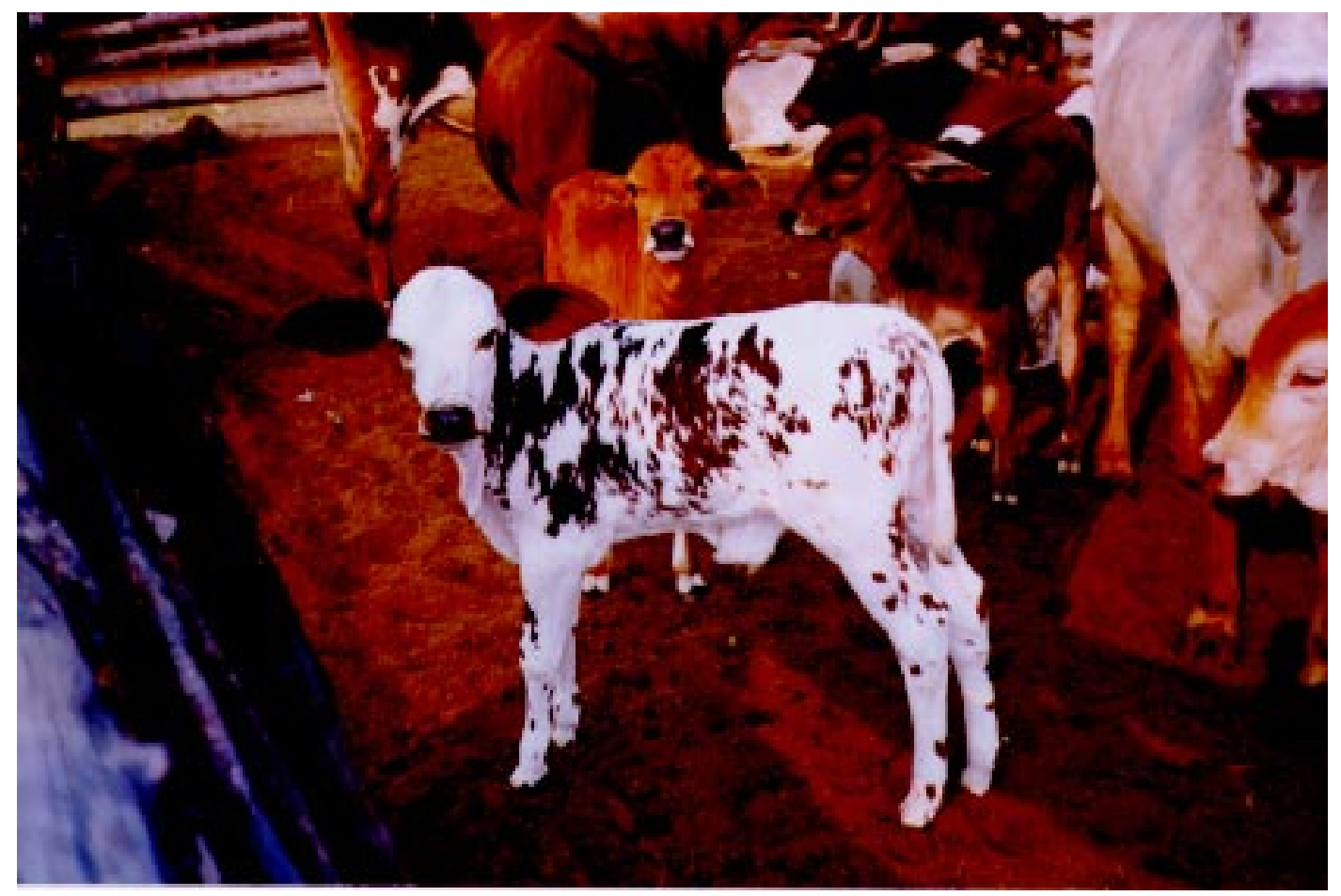

Nelore infected cattle from the Pantanal, Brazil.

on the affected ranches can be expected to lose a year of productivity.

Treatment costs and benefits - When T. vivax was diagnosed on the seven ranches, all animals on each of the ranches were treated with a diminazine aceturate. The costs of this treatment strategy include animal collection, needles and syringes, and the drug itself. Treatment costs about US\$5.38 per head-treatment.

The benefits of treating T. vivax are calculated as the present value of the cattle production saved by implementing the treatment. If the diminazine treatment had not been administered in a timely manner, at least $34.5 \%$ of the cattle on the seven ranches would have died. Treatment benefits are measured by the observed rate of infection in the outbreak multiplied by the number of brood cows potentially affected and the productivity losses averted due to treatment.

Discounted value of cattle production - An investment is an arrangement in which an individual agrees to pay something (e.g. time, money, effort) today in exchange for an expected stream of benefits sometime in the future. When the costs and benefits of an exchange take place at different points in time, it is appropriate to discount or adjust the value of future benefits to compare them with present costs. The discount or interest rate used in calculations reflects the time value of the investment. Here, we assign a discount rate of $8 \%$ as roughly reflective of the returns to alternative investments available to the rancher.

Theoretically speaking, the market price of a heifer should reflect its anticipated productivity and be equivalent to the net present value of the expected returns to its productivity. The expectation of disease loss should decrease market prices ceteris paribus. When a brood cow dies before its productive life has ended, the rancher loses the future market value of a cull cow plus the future market value of any calves the cow might have had. When a brood cow loses a year of productivity (one calf) due to infection with the disease, the rancher loses the present value of a calf sold three to four years from infection (about one year calving and two to three years to market). The financial losses due to the outbreak of $T$. vivax in the Pantanal are equivalent to the present value of the sum of these anticipated future returns calculated from the date of first investment (purchase of a brood heifer). Many Pantanal ranchers "grow" their own breeding stock. Since they must decide whether to sell their heifers or breed them, the market price of that animal category reflects the opportunity cost of the rancher's decision to breed his own cattle. 
Cattle prices - According to convention, the rancher's best guess of future prices are current prices. Here, the primary concern is with the prices of three products: productive age brood cows, old brood cows (13-14 yr old), and 2-3 yr old thin cattle. At the time of the outbreak, the local price of a productive brood cow in a very thin market was about US $\$ 200$. The 2-3 yr old thin cattle price was US\$220 and the old or unproductive cull cow price was US\$110.

Typical herd profile - In order to calculate the present value of lost productivity due to premature death of brood cows, it is necessary to know the age of the animal at its death and how many calves it was likely to produce with the rest of its life. Since this information was not available, combining information of the typical age profile of a Pantanal herd with the typical pregnancy rate by age, we can estimate the likely number of calves forgone for death at a given age. With this information we can estimate the present value of lost productivity due to this $T$. vivax outbreak. Since it is likely that the disease is distributed more or less evenly throughout the population due to its recent arrival in the region, it is logical to estimate probable losses based upon the median age of the herd.

\section{RESULTS}

Died of T. vivax before treatment - At least nine brood cows died prior to treatment for $T$. vivax. Rancher interviews indicated that all of these animals demonstrated the symptoms typical of the disease and often prompted rancher action to treat the ensuing outbreak. The financial losses due to the death of a brood cow are equivalent to the discounted value of that cow and its expected production. Using the data presented above, the present value of a $4 \mathrm{yr}$ old Pantanal brood cow is US $\$ 385$ if it produces four calves which are subsequently sold in the 2-3 yr old thin cattle market. However, on average, it is likely that closer to the median than the minimum brood cow age was killed by the outbreak. Using the median age, the present value of the losses of expected production are equal to US $\$ 153$ per deceased brood cow or a total of US $\$ 1,376$ due to the T. vivax outbreak.

Abortions - The T. vivax outbreak resulted in a total of 19 known calf abortions. The financial impact of these abortions is calculated as the discounted value of a 3 yr old calf four years in the future multiplied by the number of abortions if all of the calves would have lived to saleable age. However, since calf mortality in the absence of T. vivax in the Pantanal has been estimated at $26.7 \%$ (Almeida et al. 1996), about 14 of these 19 calves are likely to have survived. Again assuming the median age, our calculations yield a total financial impact of
US $\$ 1,419$ from abortions, or US $\$ 102$ per abortion.

Fertility loss - Pantanal brood cows have been observed to lose one year of productivity due to $T$. vivax infection. If the cow is $10 \mathrm{yr}$ old (six years from original investment), the loss of one year of productivity is roughly equivalent to the discounted value of a calf sold four years in the future (ten years from original investment); one year to calve and three years of growth. Of the 2,222 brood cows, $213(9.6 \%)$ can be expected to lose a year of productivity for an estimated loss of US\$21,705 or US\$102 per cow.

Treatment costs and benefits - Treatment represents an additional (unanticipated) investment to the rancher. The present value of treatment costs for the 2,400 cattle treated, on average, six years post investment are estimated as US\$8,131, or US\$3.39 per head.

Treatment benefits are the observed rate of infection in the outbreak multiplied by the value and number of brood cows potentially affected and the productivity losses averted due to treatment discounted to the time of the original investment from the time of treatment. Treatment benefits represent an estimate of the anticipated costs of the outbreak if treatment had not been administered. Estimated costs averted due to treatment are US $\$ 117,173$, or US\$52.73 per brood cow.

However, fertility losses were observed in infected and treated animals. As a result, the net benefits of treatment can be calculated as the total benefits less treatment costs and fertility losses, or US $\$ 87,337$ (US $\$ 39.30$ per cow) and the estimated return to investment in treatment is 10.7:1.

Extrapolation of results - The total estimated present value of the 2,222 brood cows on seven ranches in the Poconé subregion of the Brazilian Pantanal is US\$855,470. The total estimated cost of the 1995 outbreak of T. vivax on these ranches is the sum of the present values of mortality, abortion, and productivity losses and treatment costs, or US $\$ 32,631$ (US\$14.68 per brood cow or $4 \%$ of total brood cow value). If there were 11 million head of cattle in the region and all of the observed and assumed conditions in Pocone held for the rest of the region, the herd would be worth about $\$ 4$ billion and the anticipated losses to T. vivax would exceed \$160 million. Had the outbreak gone untreated, the estimated losses would have exceeded US\$140,000 (US\$63.76 per brood cow or $17 \%$ of total brood cow value) on the seven ranches, $\$ 200$ million in the Pantanal and $\$ 700$ million regionwide.

\section{CONCLUSIONS}

An estimate of the financial impact of an outbreak of T. vivax in the Poconé subregion of the 
Brazilian Pantanal in 1995 was calculated. In total, seven ranches and 2,400 potentially affected adult cattle provided the boundaries of analysis for this estimate. Costs of the outbreak fell into four categories: mortality, abortion, fertility, and treatment. The cost of fertility losses generated the greatest proportion of the estimated costs of the disease. Since cattle and calves represent investments to the rancher and the impact of T. vivax is not necessarily concurrent with either investment or infection, a present valuation of the costs of the disease was appropriate. A number of simplifying assumptions were necessary due to data restrictions in order to complete our estimations including: discount rate, cattle prices, and average brood cow age.

Although this outbreak had a small, albeit measurable, impact on the affected ranches, diagnosis and treatment of the disease is cost effective. Further, extending results to include the entire region results in fairly large damage estimates. Due to the history of the disease in other parts of the world, it is likely that future outbreaks will increase regionally warranting further research into potential control strategies for trypanosomes in the Brazilian Pantanal and the Bolivian lowlands.

\section{REFERENCES}

Almeida IL de, Abreu UGP de, Loureiro JMF, Comastri Filho JA 1996. Introdução de tecnologias na criação de bovino de corte no Pantanal: sub-região do
Paiaguás. CPAP-Embrapa, Circular Técnica 22, 50 pp.

Ogwu D, Njoku CO 1987. Effects of pregnancy on clinical manifestation of bovine trypanosomiasis. Vet Parasitol 24: 25-33.

Ogwu D, Njoku CO, Osori DIK 1986. Effects of experimental Trypanosoma vivax infection on first-, second-, and third-trimester pregnancy in heifers. Theriogenol 25: 383-398.

Ogwu D, Njoku CO, Osori DIK, Ezeokoli CD, KumiDiaka J 1984. Effects of experimental Trypanosoma vivax infection on fertility of heifers. Theriogenology 22: 625-633.

Silva RAMS, Da Silva JA, Schneider RC, De Freitas J, Mesquita DP, Mesquita TC, Ramirez L, Dávila AMR, Pereira MEB 1995. Bovine trypanosomosis due to Trypanosoma vivax in the northern subregion of Pantanal, Brazil. Trypnews 2:1-2.

Silva RAMS, Da Silva JA, Schneider RC, De Freitas J, Mesquita D, Mesquita T, Ramirez L, Dávila AMR, Pereira MEB 1996. Outbreak of trypanosomiasis due to Trypanosoma vivax (Ziemann, 1905) in bovines of the Pantanal, Brazil. Mem Inst Oswaldo Cruz 5: 561-562.

Silva RAMS, Egüez A, Morales G, Eulert E, Montenegro A, Ybañez R, Seidl A, Dávila AMR, Ramirez L 1998a. Bovine trypanosomiasis in the Bolivian and Brazilian lowlands. Mem Inst Oswaldo Cruz 93: 2932.

Silva RAMS, Morales G, Eulert E, Montenegro A, Ybañez R 1998b. Outbreaks of trypanosomiasis due to Trypanosoma vivax in cattle in Bolivia. Vet Parasitol 76:153-157. 